\title{
Influência da configuração de instalação dos trocadores de calor na operação de um secador assistido por bomba de calor
}

\author{
Influence of the installation configuration of heat exchangers on the operation of a heat pump \\ assisted dryer
}

Influencia de la configuración de instalación de intercambiadores de calor en el funcionamiento de una secadora asistida por bomba de calor

Rodrigo Aparecido Jordan

ORCID: https://orcid.org/0000-0002-2479-4461

Universidade Federal da Grande Dourados, Brasil

E-mail: rodrigojordan @ufgd.edu.br

Wellytton Darci Quequeto

ORCID: https://orcid.org/0000-0002-0658-2692 Instituto Federal de Ciência, Educação e Tecnologia Goiano, Brasil

E-mail: wellytton_quequeto@hotmail.com

Anamari Viegas de Araujo Motomia

ORCID: https://orcid.org/0000-0003-2170-8676

Universidade Federal da Grande Dourados, Brasil

E-mail: AnamariMotomiya@ufgd.edu.br

Valdiney Cambuy Siqueira

ORCID: https://orcid.org/0000-0003-3698-0330

Universidade Federal da Grande Dourados, Brasil

E-mail: vcambuy@yahoo.com

Elton Aparecido Siqueira Martins

ORCID: https://orcid.org/0000-0002-3195-2317

Universidade Federal da Grande Dourados, Brasil

E-mail: eltonmartins@ufgd.edu.br

Ítalo Sabião Sanches

ORCID: https://orcid.org/0000-0002-3212-6199

Universidade Federal da Grande Dourados, Brasil

E-mail: italosabiao@hotmail.com

Édipo Sabião Sanches

ORCID: https://orcid.org/0000-0003-0783-772X

Universidade Federal da Grande Dourados, Brasil

E-mail: ediposabiao@hotmail.com

Bruno Machado Antunes

ORCID: https://orcid.org/0000-0002-4222-0787

Universidade Federal da Grande Dourados, Brasil

E-mail: bruno.m.antunes@anhanguera.com

\begin{abstract}
Resumo
Foi desenvolvido e montado em laboratório, um protótipo de secador com bomba de calor de pequena capacidade, para secagem de produtos termossensíveis, com sistema de refrigeração acoplado a uma câmara com isolamento térmico, fixados em uma única estrutura. Foram testadas duas opções de montagem do sistema de troca de calor no interior da câmara de secagem. Na primeira opção (configuração 1), trabalhou-se numa configuração com um único trocador de calor, o qual alternava a função de evaporador e condensador, em ciclos de resfriamento e aquecimento, através do emprego de uma válvula de quatro vias. Na segunda opção (configuração 2), trabalhou-se numa configuração com dois trocadores de calor, onde o ar passava primeiramente pelo evaporador e, depois, pelo condensador. As configurações foram avaliadas segundo as condições psicrométricas de operação: temperatura, umidade relativa e umidade de equilíbrio do ar. A configuração 2 mostrou-se mais efetiva quanto ao condicionamento do ar de secagem, com condições psicrométricas mais favoráveis, resultando em menores valores médios de umidade de equilíbrio.
\end{abstract}

Palavras-chave: Baixa temperatura; Equilíbrio higroscópico; Psicrometria. 


\begin{abstract}
A prototype of a dryer with a small capacity heat pump was developed and assembled in the laboratory, for drying thermosensitive products, with a refrigeration system coupled to a thermally insulated chamber, fixed to a single structure. Two options for mounting the heat exchange system inside the drying chamber were tested. In the first option (configuration 1), a configuration with a single heat exchanger was used, which alternated the function of evaporator and condenser, in cooling and heating cycles, through the use of a four-way valve. In the second option (configuration 2), a configuration with two heat exchangers was used, where the air passed first through the evaporator and then through the condenser. The settings were evaluated according to the psychrometric operating conditions: temperature, relative humidity and equilibrium air humidity. Configuration 2 was more effective in conditioning the drying air, with more favorable psychrometric conditions, resulting in lower average equilibrium moisture values.
\end{abstract}

Keywords: Low temperature; Hygroscopic balance; Psychrometrics.

\title{
Resumen
}

Se desarrolló y ensambló en laboratorio un prototipo de secador con bomba de calor de pequeña capacidad, para el secado de productos termosensibles, con un sistema de refrigeración acoplado a una cámara aislada térmicamente, fijada a una sola estructura. Se probaron dos opciones para montar el sistema de intercambio de calor dentro de la cámara de secado. En la primera opción (configuración 1) se utilizó una configuración con un solo intercambiador de calor, que alternaba la función de evaporador y condensador, en los ciclos de enfriamiento y calentamiento, mediante una válvula de cuatro vías. En la segunda opción (configuración 2), trabajamos en una configuración con dos intercambiadores de calor, donde el aire pasa primero por el evaporador y luego por el condensador. Los ajustes se evaluaron de acuerdo con las condiciones operativas psicrométricas: temperatura, humedad relativa y humedad del aire en equilibrio. La configuración 2 fue más efectiva en el acondicionamiento del aire de secado, con condiciones psicrométricas más favorables, lo que resultó en valores promedio de humedad de equilibrio más bajos.

Palabras clave: Baja temperatura; Equilibrio higroscópico; Psicrometría.

\section{Introdução}

Notadamente, as bombas de calor são equipamentos muito eficientes quando se trata de aquecimento, isso pelo fato de não converterem a energia elétrica diretamente em calor e, sim, fazer uso desta para retirar calor de uma fonte a baixa temperatura e rejeitá-lo em um depósito a temperatura mais elevada. Com isso, as bombas de calor conseguem produzir de 3 a 7 vezes mais calor que uma resistência elétrica de mesma potência, o que implica dizer que uma bomba de calor pode substituir uma resistência elétrica consumindo de um terço a um sete avos da potência desta (Sarkar et al., 2006; Aktas et al.; 2014; Yuan et al., 2019). Isto faz com que a bombas de calor de calor também sejam opções mais vantajosas frente a queima direta de óleo e gás para aquecimento (Jordan et al., 2016, Jordan et al., 2019).

Referenciadas pelo seu desempenho em processos de aquecimento, onde é utilizado como efeito útil apenas o calor dissipado pelo condensador, no processo de secagem, as bombas de calor passam a ter outra função importante, que é a redução da pressão de vapor do ar através do efeito combinado de resfriamento e aquecimento (Patel \& Kar, 2012), onde o evaporador resfria o ar abaixo do ponto de orvalho, agindo como um desumidificador, reduzindo a razão de mistura. O condensador tem a função de reaquecer o ar, reduzindo o valor de umidade relativa, conferindo uma condição de umidade de equilíbrio higroscópico baixa, mesmo em baixa temperatura (Lewis, 2003; Pal \& Khan, 2010; Lee et al., 2010; Minea, 2011).

Já é conhecida a importância do processo de secagem nas etapas de pós-colheita, tendo em vista tanto a questão de formação de custos, no que se refere ao consumo de energia (Mellmann \& Fürll; 2008; Minea, 2015), quanto à questão da preservação da qualidade do produto (Alves, 2013, Borém et al., 2018; Kulapichitr et al., 2019). Nesse sentindo, pesquisas vêm sendo realizadas com o objetivo de desenvolver equipamentos e técnicas que possibilitem a obtenção de um produto de boa qualidade sem aumentar o consumo de energia, ou até mesmo, com possibilidade de redução do consumo de energia, onde o tempo de processo também é uma preocupação (Juan et al., 2013; Dong et al., 2017; Gümüşay et al., 2015; Dong et al., 2019; Jeyaprakash, 2019; Jordan et al., 2020a; Jordan et al., 2020b).

O processo de secagem, quando conduzido de maneira inadequada, pode resultar na degradação dos produtos, como 
oxidação, descoloração, perda de massa, alteração do valor nutricional e de componentes químicos (Gümüşay et al., 2015), onde a temperatura exerce um papel importante (Cruz et al., 2012).

A temperatura é o parâmetro levado em maior consideração quando se objetiva reduzir o tempo de secagem. Porém, temperaturas elevadas são prejudiciais para produtos termossensíveis (Jordan et al., 2020c; Jordan et al., 2020d). Assim, se fazem necessários sistemas de secagem que possam operar com baixas temperaturas (Ziegler et al., 2013; Taşeri et al., 2018). No entanto, os secadores convencionais não conseguem propiciar tal condição. Por serem baseados em aquecimento sensível, ficam suscetíveis a condição de umidade relativa do ar, necessitando por isso, operar em temperaturas mais elevadas para garantir a eficiência do processo de secagem (Jordan et al., 2020b).

Sistemas de secagem com bombas de calor se mostram eficazes para atuar em baixas temperaturas, mantendo uma baixa umidade relativa, sem a elevação dos parâmetros de temperatura e fluxo do ar (Aktas et al., 2014). Além do mais, estes sistemas resultam em produtos com melhor qualidade e menor consumo de energia (Coşkun et al., 2016).

Neste contexto, objetivou-se com o presente trabalho avaliar o desempenho operacional de um protótipo de secador com bomba de calor sob duas configurações de montagem do sistema de troca de calor e remoção de umidade da câmara de secagem.

\section{Metodologia}

O experimento foi conduzido no LTRE - Laboratório de Termodinâmica, Refrigeração e Energia da Faculdade de Ciências Agrárias (FCA) da Universidade Federal da Grande Dourados - UFGD. O secador foi montado utilizando-se componentes de refrigeração de um aparelho de ar condicionado de 12000 BTU (referência comercial), o que equivale a 3,52 $\mathrm{kW}$ de potência térmica de resfriamento, com uma potência elétrica de $1,75 \mathrm{~kW}$, implicando em uma potência térmica estimada, de 5,25 kW para aquecimento. O Fluído refrigerante era o R22.

Como câmara de secagem foi utilizada o gabinete de uma estufa elétrica de aquecimento com dimensões (base $\mathrm{x}$ altura x profundidade) de $80 \times 100 \times 60 \mathrm{~cm}$. Para isso as resistências elétricas foram removidas para dar espaço aos trocadores de calor. A câmara de secagem foi montada sob uma base móvel, construída em metal para essa finalidade (Figura 1). Na base foi fixado o compressor de refrigeração hermético, o quadro elétrico e outros componentes do sistema de refrigeração.

Figura 1 - Protótipo de secador, câmara de secagem montada sob a base onde se encontra parte do sistema de refrigeração.

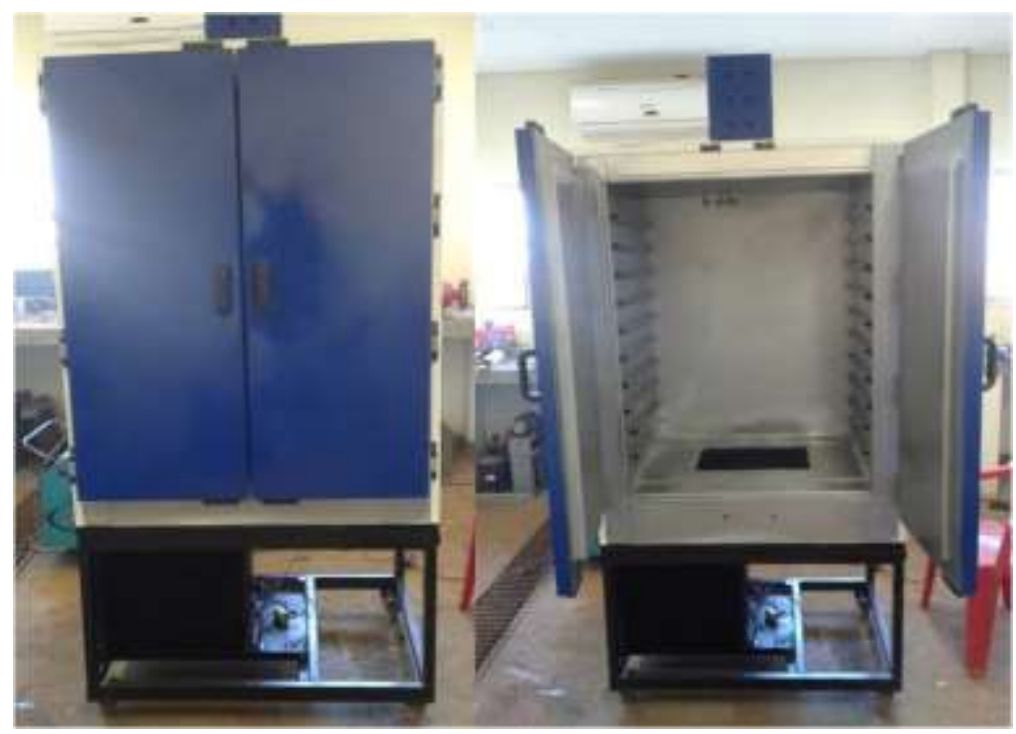

Fonte: Autores (2021). 
Foi adotado o sistema de recirculação em circuito fechado, sem renovação do ar da câmara de secagem. Foram montadas duas configurações de troca de calor e remoção de água da câmara de secagem: a primeira (configuração 1), com um único trocador de calor fazendo a função de evaporador e condensador, de modo alternado; a segunda (configuração 2), utilizando trocadores distintos para o evaporador e condensador.

A Figura 2 apresenta o esquema conceitual de funcionamento do secador na configuração 1.

Figura 2 - Esquema conceitual de funcionamento do secador na configuração 1.

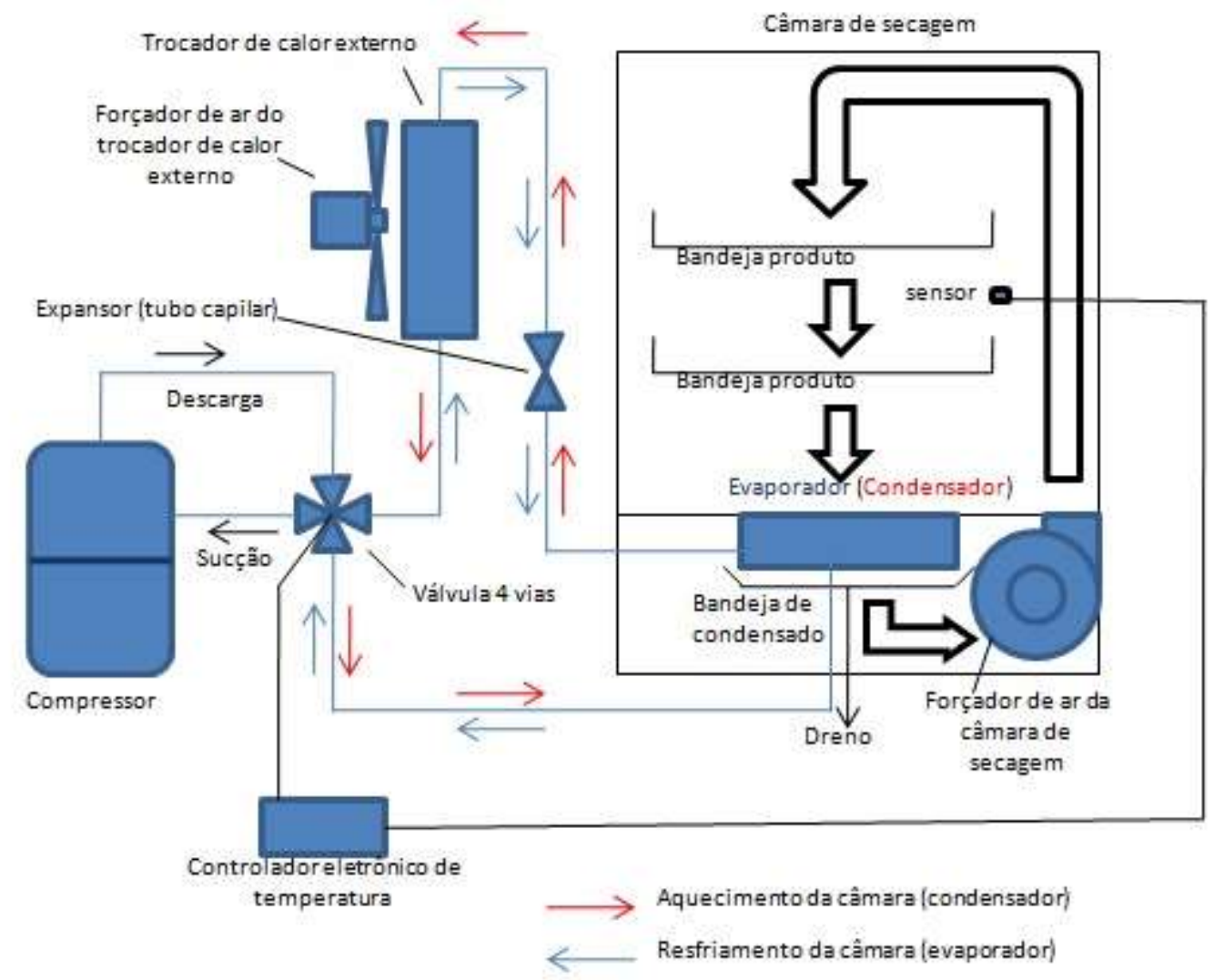

Fonte: Autores (2021).

A válvula 4 vias, acionada eletricamente sob o comando do controlador eletrônico de temperatura, faz a mudança de função do trocador interno. O sensor informa a temperatura da câmara ao controlador eletrônico de temperatura. Estando o valor abaixo do programado, a válvula 4 vias é acionada e o fluxo de fluído refrigerante se dá no sentido de aquecimento da câmara, com o trocador interno operando como condensador. Quando a temperatura programada é atingida, a válvula 4 vias é desligada, invertendo o sentido do fluxo de fluído refrigerante, fazendo com que o trocador de calor interno passe a operar como evaporador, resfriando o ar da câmara e provocando a condensação da água que é coletada numa bandeja de condensado e removida por um dreno. Assim, a frequência da alternância se dá em função do diferencial de temperatura programado.

Na configuração 2 (Figura 3), o controle de temperatura passou a ser feito através de um condensador externo, com aproximadamente $35 \%$ da capacidade de condensação. Na parte inferior da câmara de secagem foi instalado o evaporador e um segundo condensador (condensador interno), este com aproximadamente 65\% da capacidade de condensação. O ar, após passar pelas bandejas com o produto, seguia primeiro para o evaporador, para resfriamento e condensação da água e, depois, para o condensador, onde era reaquecido e tinha sua umidade relativa reduzida. O diferencial de temperatura passou ser controlado pelo acionamento do ventilador do condensador externo, modulando assim o fluxo de calor para o interior da câmara. Uma vez 
atingida a temperatura programada, esse ventilador era acionado, reduzindo o fluxo de calor na câmara de secagem. Quando a temperatura atingia o valor mínimo segundo o diferencial programado, o ventilador era desligado, e o fluxo de calor para a câmara de secagem aumentava novamente.

Figura 3 - Esquema conceitual de funcionamento do secador na configuração 2.

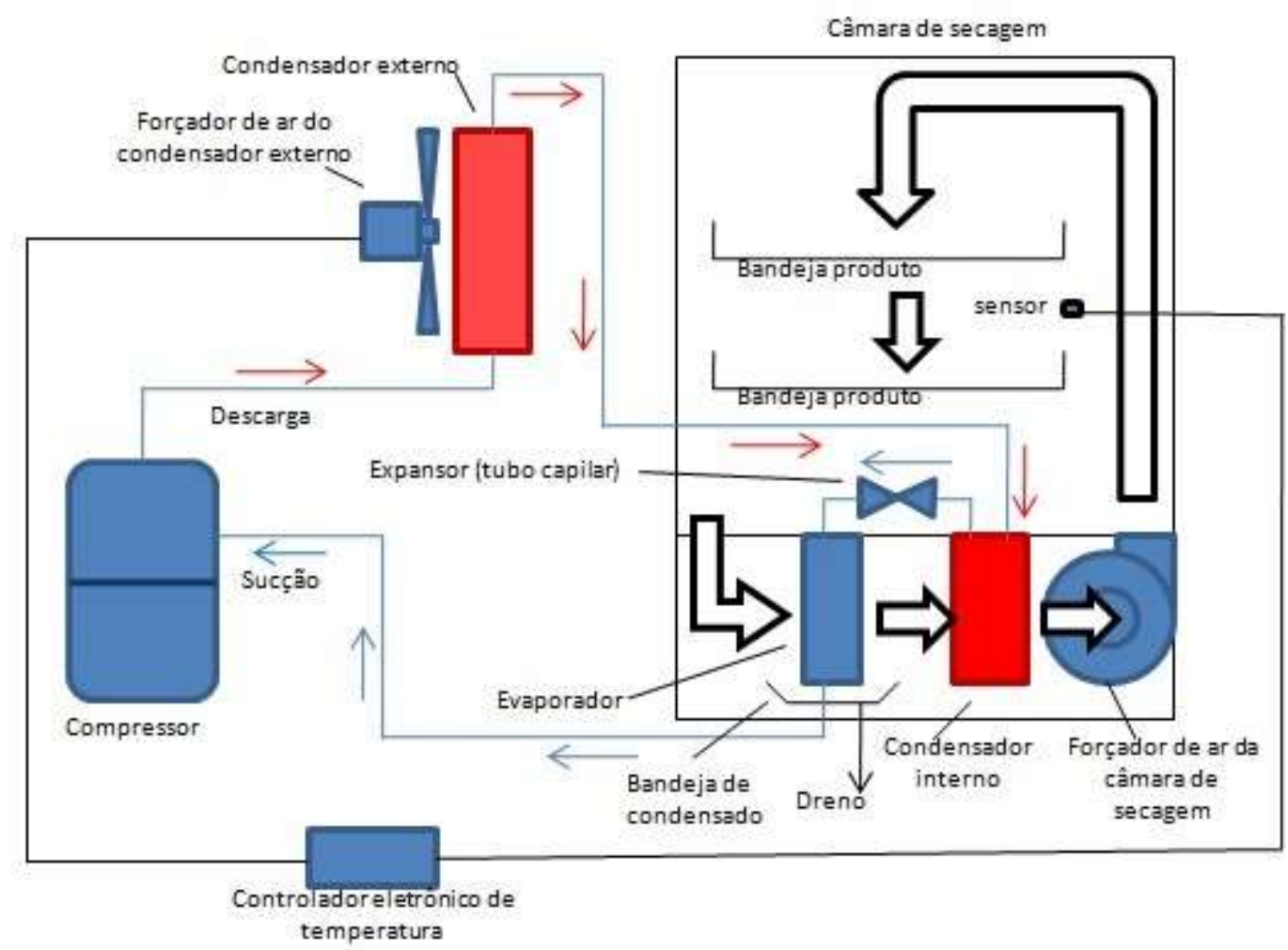

Fonte: Autores (2021).

A configuração 1 foi a primeira a ser montada. Após instrumentação e testes de operação com o secador, a configuração 1 foi desmontada e, no seu lugar, montada a configuração 2 , sendo o secador novamente submetido a testes de operação. Os testes de operação foram realizados com a câmara de secagem sem produto, ou seja, com o secador vazio.

A instrumentação (Figura 4) foi composta por sensores de temperatura e umidade relativa instalados no interior da câmara de secagem, os quais foram conectados a um módulo de aquisição de dados ligado a um computador que, através de um software específico, fazia a gravação dos dados para posterior análise. 
Figura 4 - Sistema de aquisição de dados conectado ao computador (a), sensores de temperatura e umidade relativa na câmara de secagem (b).

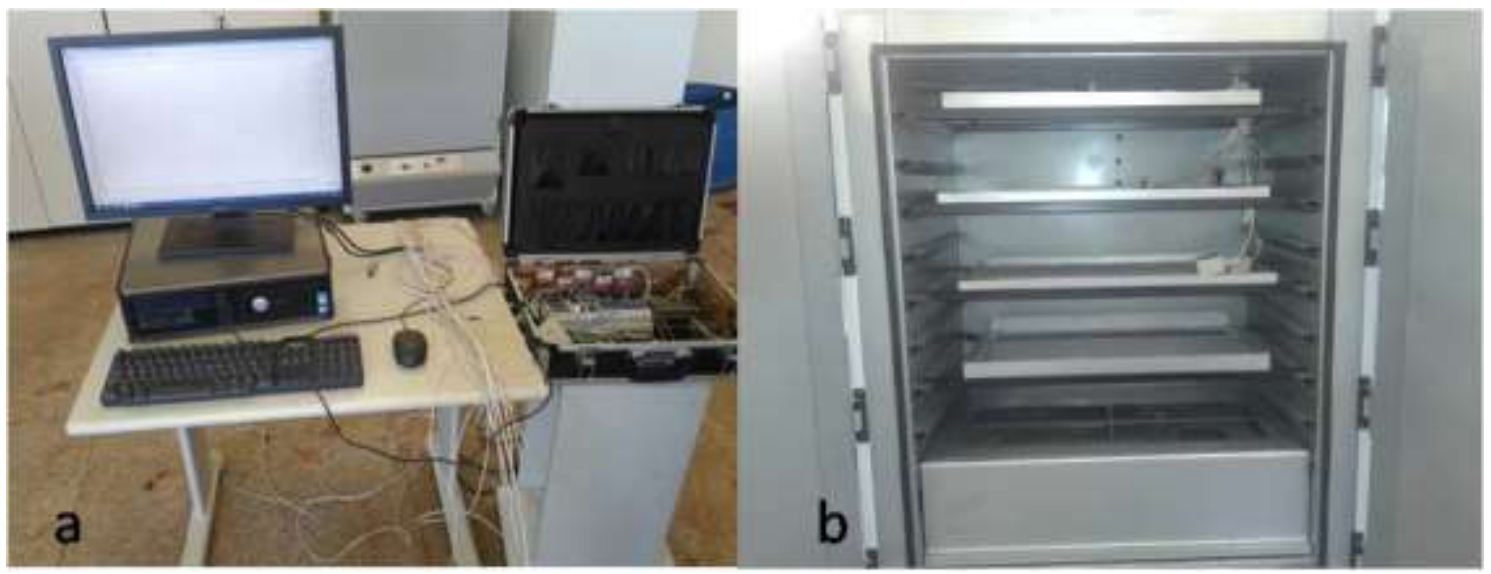

Fonte: Autores (2021).

A análise da condição do ar dentro da câmara de secagem se deu através dos dados de temperatura e umidade relativa, os quais foram transformados em gráficos para melhor visualização dos processos. O potencial de secagem do ar foi avaliado através dos valores de umidade de equilíbrio $\left(\mathrm{U}_{\mathrm{e}}\right)$, calculados através da Equação 1, de Chung e Pfost (1967), a partir dos valores de temperatura e umidade relativa. Os dados utilizados para análise foram tomados na condição de regime de operação estável do secador. Para isso, em cada teste, após ligar o secador na condição programada, esperava-se o tempo de estabilização, para assim começar a fazer aquisição dos dados.

\section{$\mathrm{U}_{\mathrm{z}}=\mathrm{a}-\mathrm{b} \ln [-(\mathrm{T}+\mathrm{c}) \ln (\mathrm{UR})]$}

Em que:

$\mathrm{T}$ : temperatura do ar, ${ }^{\circ} \mathrm{C}$;

UR: umidade relativa do ar (decimal);

a,b e c: coeficientes do modelo.

Foram adotados para a Equação 1 os valores dos coeficientes para a predição da umidade de equilíbrio para café (a= 0,35; b =0,058, c = 50,555). Os dados foram submetidos à análise de variância (teste F) ao nível de significância de 5\%, considerando-se o delineamento inteiramente casualizado. Para a comparação entre os tratamentos, efetuou-se o teste de Tukey ao nível de significância de $5 \%$ de probabilidade. Os procedimentos estatísticos foram realizados com o pacote ANOVA OneWay e emmeans (Lenth, 2021) disponível no software estatístico R (R Development Core Team, 2014).

\section{Resultados e Discussão}

A Figura 5 mostra o comportamento da umidade relativa e da temperatura na câmara de secagem durante a operação do secador na configuração 1 , com temperatura programada para $50{ }^{\circ} \mathrm{C}\left(\mathrm{T}_{\text {máx }}\right)$ e diferencial de temperatura $(\Delta \mathrm{T})$ de $30{ }^{\circ} \mathrm{C}$. As diferenças verificadas entre os valores de temperatura programados e os medidos, se devem a diferença de resposta entre os sensores do controlador e do sistema de aquisição de dados e, a inércia térmica da câmara.

O diferencial mínimo $(\Delta \mathrm{T})$ de $30^{\circ} \mathrm{C}$ foi estabelecido durante os testes. Valores inferiores resultaram em ciclos muito curtos, ou seja, uma frequência de alternância entre resfriamento (processo 1 - 2) e aquecimento (processo 2 - 4) muito elevada. Houve receio de que isso pudesse causar danos a válvula 4 vias ou, mesmo, ao compressor. 
Figura 5 - Comportamentos de temperatura e umidade relativa na câmara de secagem durante operação do secador na configuração $1\left(\mathrm{~T}_{\text {máx }}=50^{\circ} \mathrm{C}, \Delta \mathrm{T}=30^{\circ} \mathrm{C}\right)$.

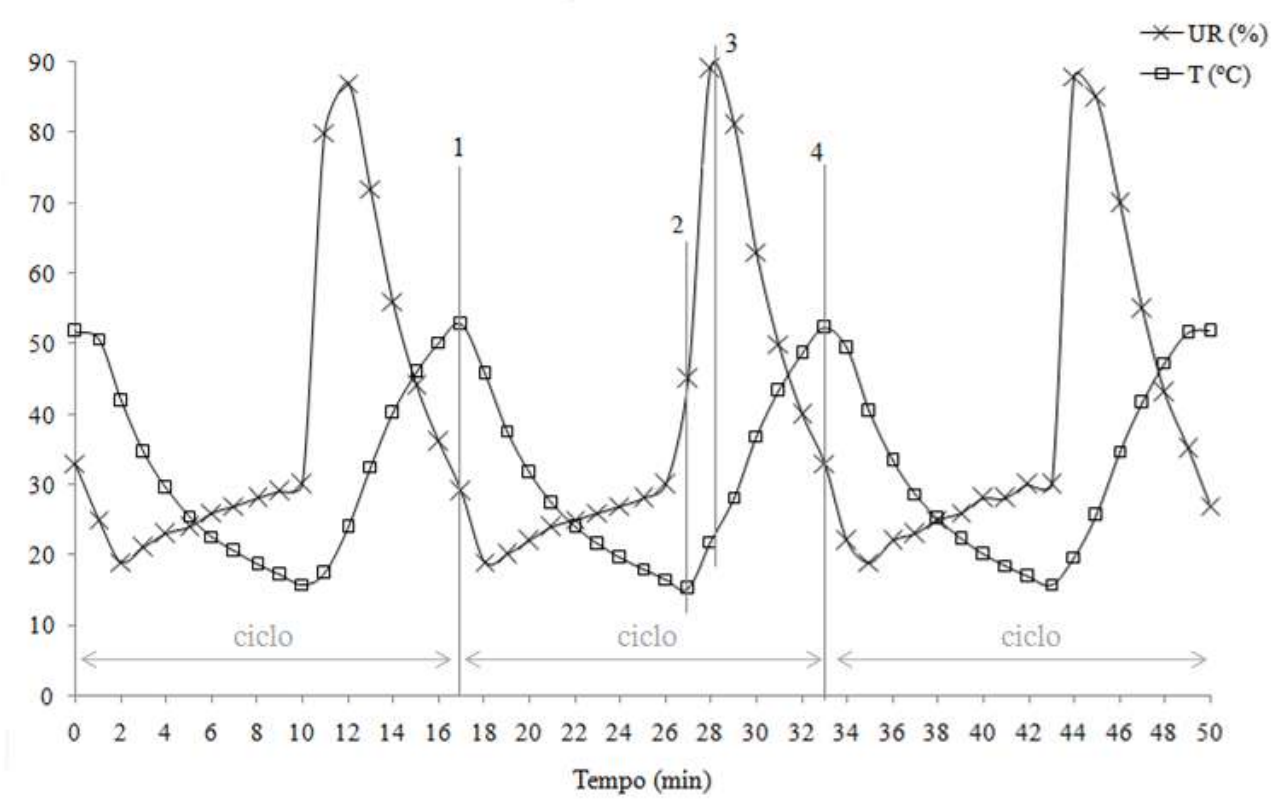

Fonte: Autores (2021).

Analisando o ciclo e os processos da Figura 5, chama a atenção, a elevação brusca da umidade relativa entre o final do processo de resfriamento e início do processo de aquecimento (processo 2 - 3), atingindo um valor próximo de $90 \%$. A causa do problema era água condensada no processo de resfriamento, ainda presente no trocador de calor, a qual era rapidamente evaporada pelo processo de aquecimento e reabsorvida pelo ar. A mudança repentina de função (resfriamento para aquecimento), não permitia tempo suficiente para a drenagem da água.

A Figuras 6 mostra o comportamento de umidade relativa e temperatura dentro da câmara de secagem para as condições de operação na configuração 2: (A) temperatura programada de $40{ }^{\circ} \mathrm{C}$ e diferencial de temperatura $(\Delta \mathrm{T})$ de $2{ }^{\circ} \mathrm{C}$; $(\mathrm{B})$ temperatura programada de $40^{\circ} \mathrm{C}$ e diferencial de temperatura $(\Delta \mathrm{T})$ de $5{ }^{\circ} \mathrm{C}$; e, (C) temperatura programada de $45^{\circ} \mathrm{C}$ e diferencial de temperatura $(\Delta \mathrm{T})$ de $1{ }^{\circ} \mathrm{C}$. Para essas condições, os valores de umidade relativa variaram entre 30 e $38 \%$. A menor amplitude foi obtida para a condição com menor diferencial de temperatura (Figura 6C), com valores de umidade relativa variando entre 30 e $34 \%$. 
Research, Society and Development, v. 10, n. 16, e378101623929, 2021

(CC BY 4.0) | ISSN 2525-3409 | DOI: http://dx.doi.org/10.33448/rsd-v10i16.23929

Figura 6 - Comportamentos de temperatura e umidade relativa na câmara de secagem durante operação do secador na configuração 2 .
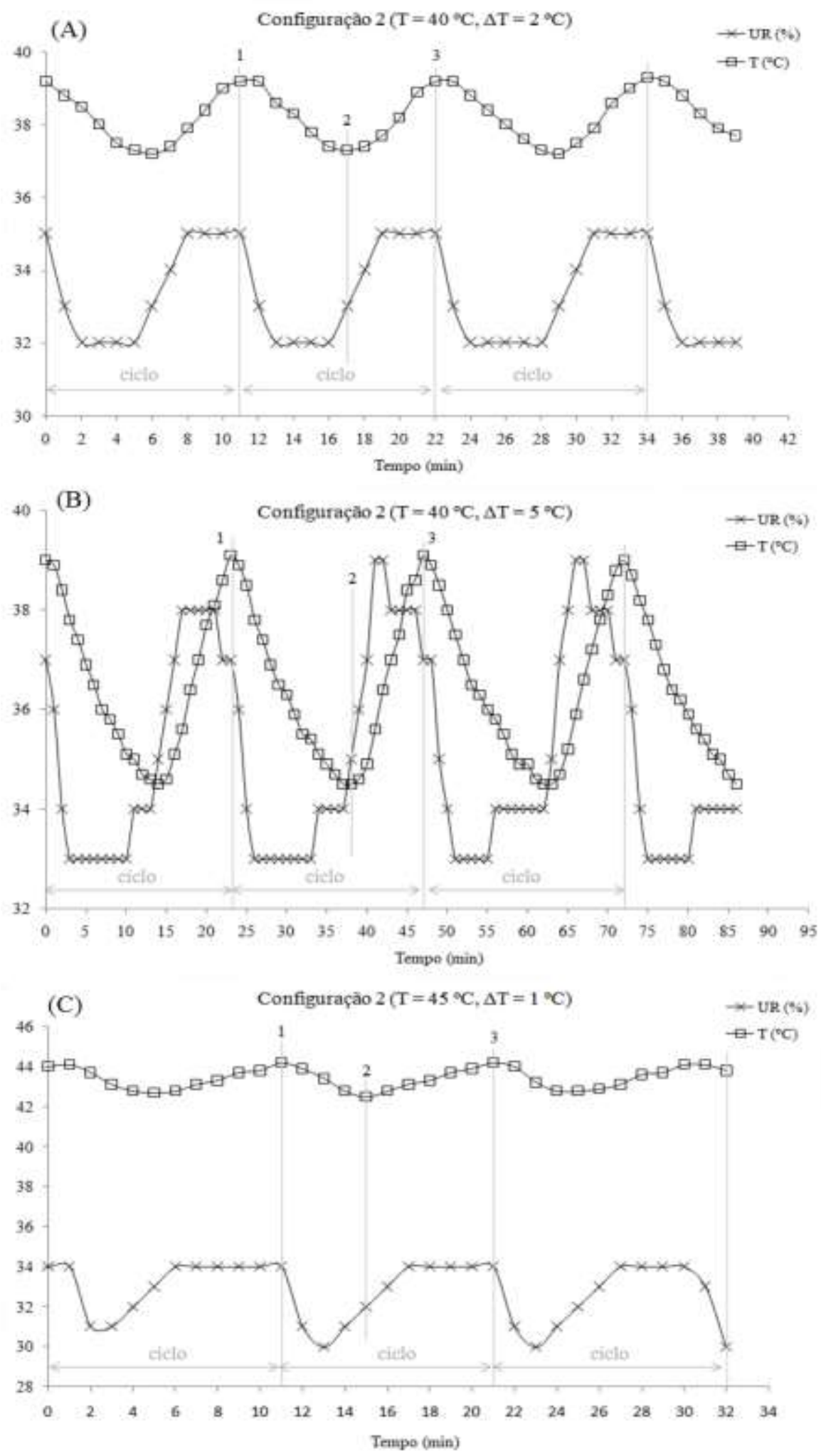

Fonte: Autores (2021).

Observa-se na Figura 6, que durante os processos de resfriamento (processo 1 - 2) e aquecimento (processo 2 - 3 ), a 
umidade relativa apresentou comportamento semelhante em todas as condições (A, B e C). Esse comportamento diferiu totalmente do observado para a configuração 1 (Figura 5), onde a umidade relativa, seguindo o comportamento normal dos processos psicrométricos, aumentou com o resfriamento e tendeu a diminuir durante o processo de aquecimento, exceto pela situação de reabsorção de água (processo 2 - 3), a qual interferiu, levando a um processo de aquecimento com umidificação.

Para todas as condições na configuração 2, observa-se que a umidade relativa tendeu a diminuir durante o processo de resfriamento, evidenciando um processo de resfriamento com desumidifição e, no processo de aquecimento, a umidade relativa tendeu a aumentar, evidenciando um processo de aquecimento com umidificação. Essa característica tem relação com a montagem do evaporador em série com o condensador em circuito fechado de ar, com o ar passando primeiro pelo evaporador e depois pelo condensador.

Durante o processo de resfriamento, o fluxo de calor diminui no condensador interno, porém, ainda provocando reaquecimento, reduzindo o valor da umidade relativa. Durante o processo de aquecimento, o fluxo de calor no condensador aumenta, assim, o ar retorna mais quente para o evaporador, fazendo a água condensada, presente nas aletas desse trocador e na bandeja, evaporar, provocando o processo de umidificação durante o aquecimento, pela reabsorção da água condensada.

Porém, observa-se que em todas as condições houve uma região de inflexão onde a umidade relativa estabiliza e, depois, volta a aumentar no final do processo de resfriamento. A Figura 7 que mostra o comportamento da razão de mistura do ar em relação à temperatura e a umidade relativa durante um ciclo de resfriamento e aquecimento para a condição de $40{ }^{\circ} \mathrm{C}$ e diferencial de $5^{\circ} \mathrm{C}$, ajuda entender esse comportamento. Verifica-se que o aumento da umidade relativa no final do processo de resfriamento, coincide com o início do aumento da razão de mistura do ar.

Analisando as curvas de razão de mistura do ar para os ciclos de resfriamento e aquecimento em todas as configurações e condições (Figura 8), fica evidente que a reabsorção de água condensada, não ocorreu apenas na configuração 1. É possível ver que em todas as condições da configuração 2, a razão de mistura tendeu a retornar ao mesmo valor do início do ciclo. Salvo a possibilidade de ter havido um mínimo de infiltração de ar externo na câmara, esse comportamento evidencia a reabsorção de água condensada.

Figura 7 - Comportamento da razão de mistura do ar em relação à temperatura e a umidade relativa durante um ciclo (resfriamento e aquecimento) para a configuração 2 na temperatura de $40{ }^{\circ} \mathrm{C}$ e diferencial de $5{ }^{\circ} \mathrm{C}$.

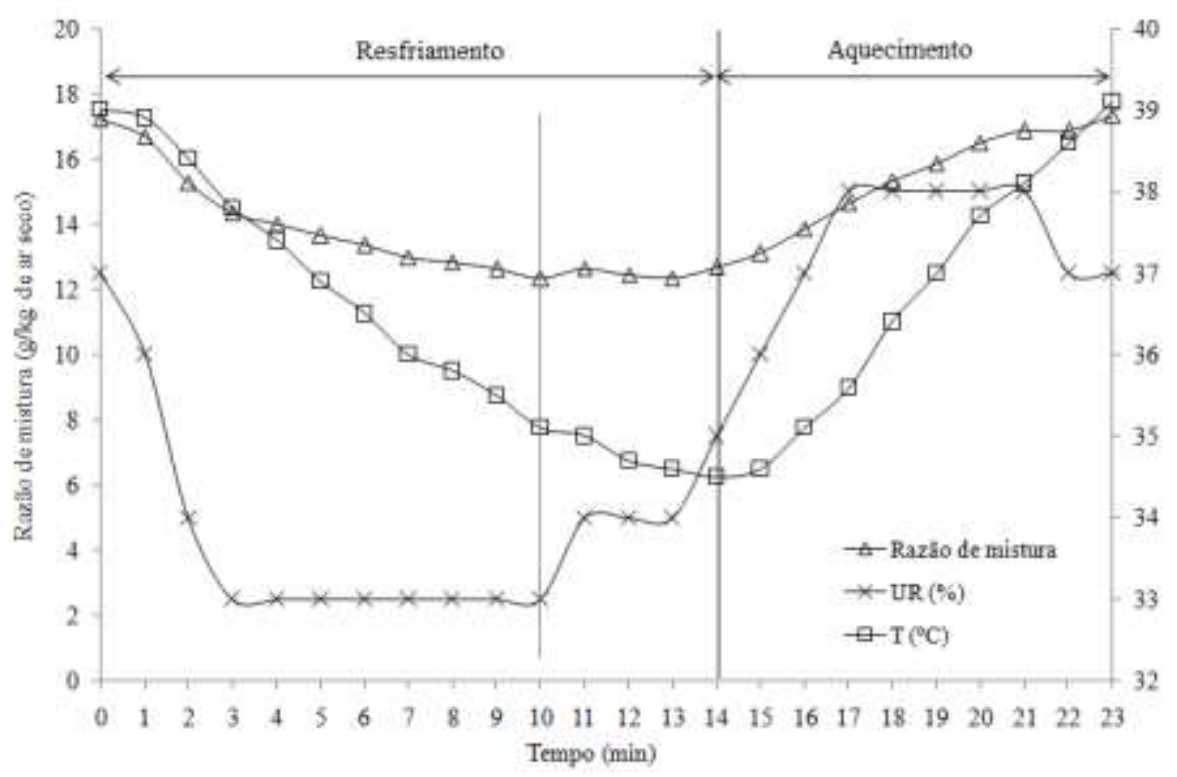

Fonte: Autores (2021). 
Research, Society and Development, v. 10, n. 16, e378101623929, 2021

(CC BY 4.0) | ISSN 2525-3409 | DOI: http://dx.doi.org/10.33448/rsd-v10i16.23929

Figura 8 - Curvas de razão de mistura do ar para os ciclos de resfriamento e aquecimento para todas as configurações e condições de operação.

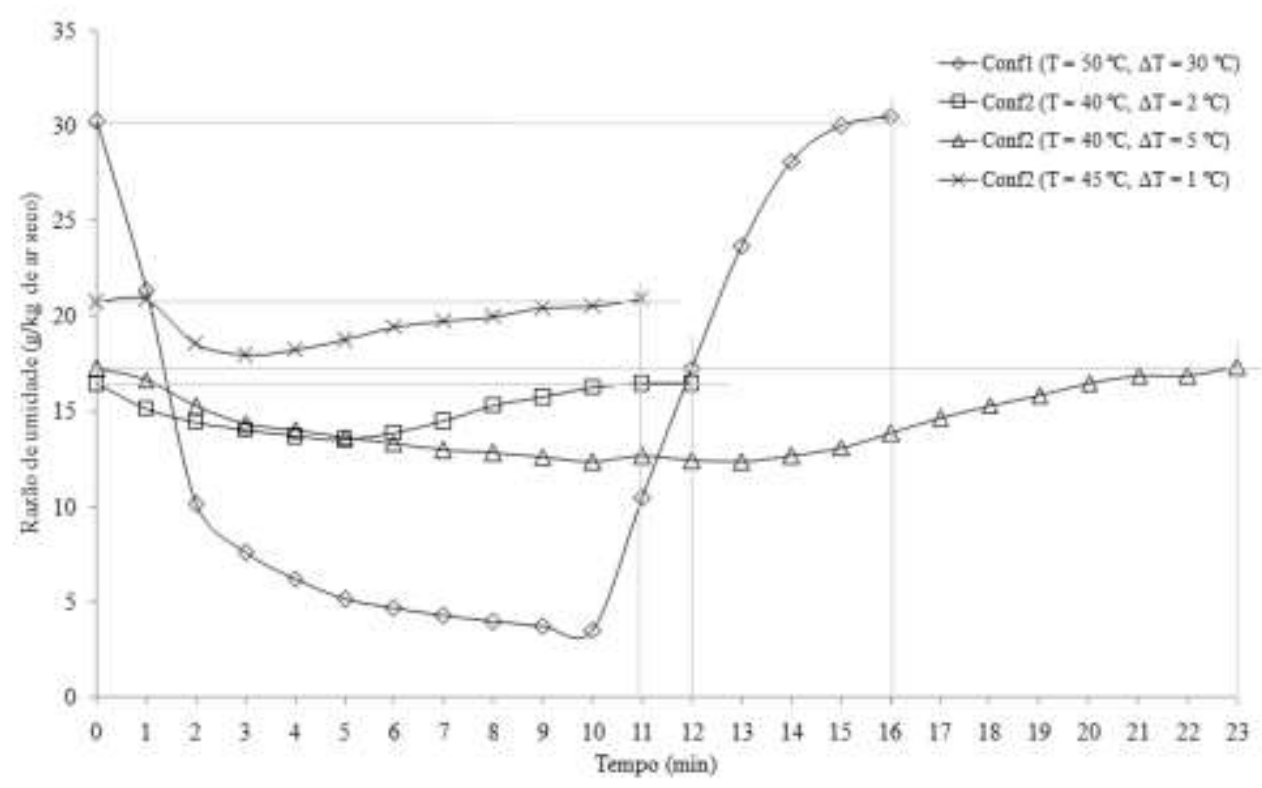

Fonte: Autores (2021).

$\mathrm{Na}$ configuração 2, a reabsorção de água está relacionada a forma como os trocadores de calor (evaporador e condensador interno) foram montados (Figura 9), muito próximos, formando um único módulo sobre uma bandeja, o que facilitou a passagem de água condensada no evaporador para o condensador. $\mathrm{O}$ fato de o condensador ter ficado sobre a bandeja, também contribuiu.

Figura 9 - Módulo de condicionamento de ar utilizado na montagem da configuração 2, composto por evaporador, condensador, forçador de ar e bandeja de recolhimento de condensado.

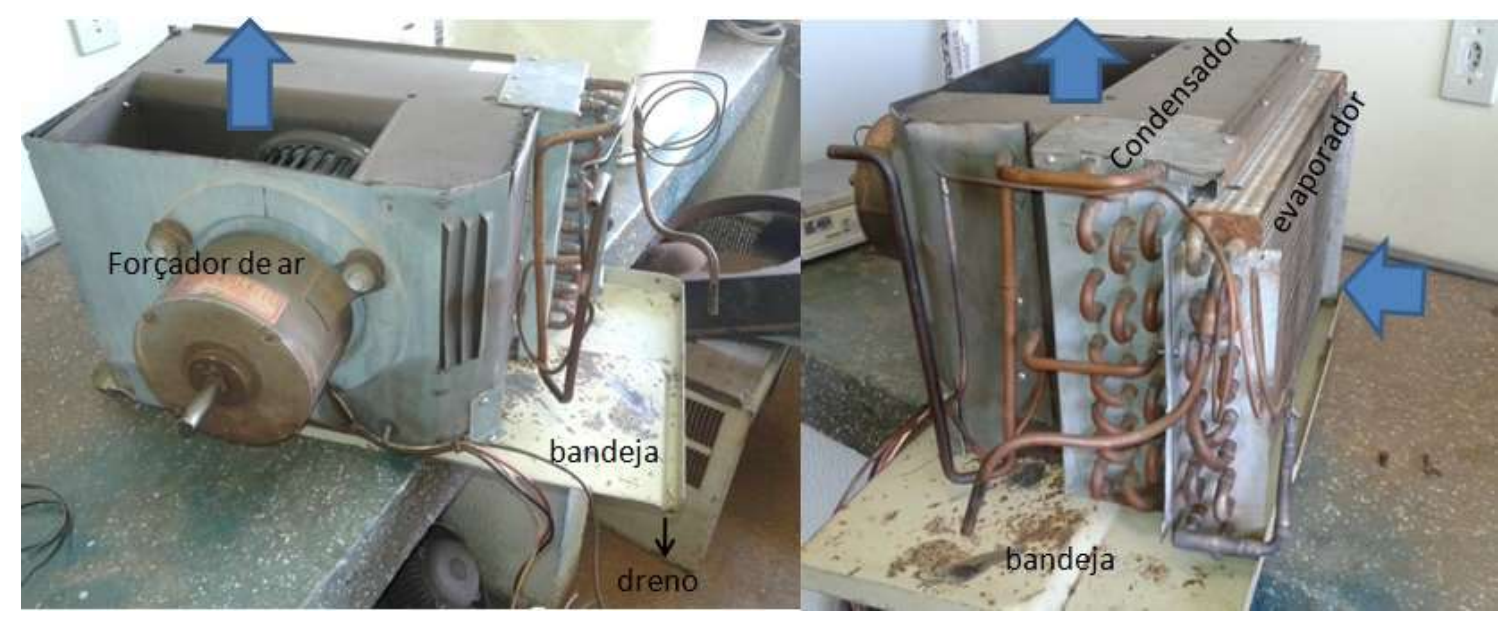

Fonte: Autores (2021).

É possível também observar na Figura 8, como o aumento do diferencial de temperatura afetou a duração do ciclo (resfriamento/aquecimento) na configuração de montagem 2, aumentando a sua duração, além de aumentar a amplitude dos valores.

Mesmo também tendo apresentado o problema de reabsorção de água, a configuração 2 apresentou os menores 
valores de umidade de equilíbrio em todas as condições (Figura 10A), com menor amplitude e oscilação durante o tempo de operação, se diferenciando da configuração 1, onde o Teste de Tukey (Figura 10B) apontou não ter havido diferença significativa entre as médias dos seus tratamentos (condições de operação), sendo respectivamente iguais a 8,76, 8,42 e 8,02 para T2, T3 e T4. Na Figura 10B, as barras cinzas indicam o intervalo de confiança para a média (5\% de probabilidade), enquanto o ponto é a própria média de cada tratamento.

Figura 10 - Comportamento da umidade de equilíbrio bu (\%) do ar da câmara de secagem, para cada configuração e condição de operação: (A) curvas de operação; (B) Teste de Tukey.

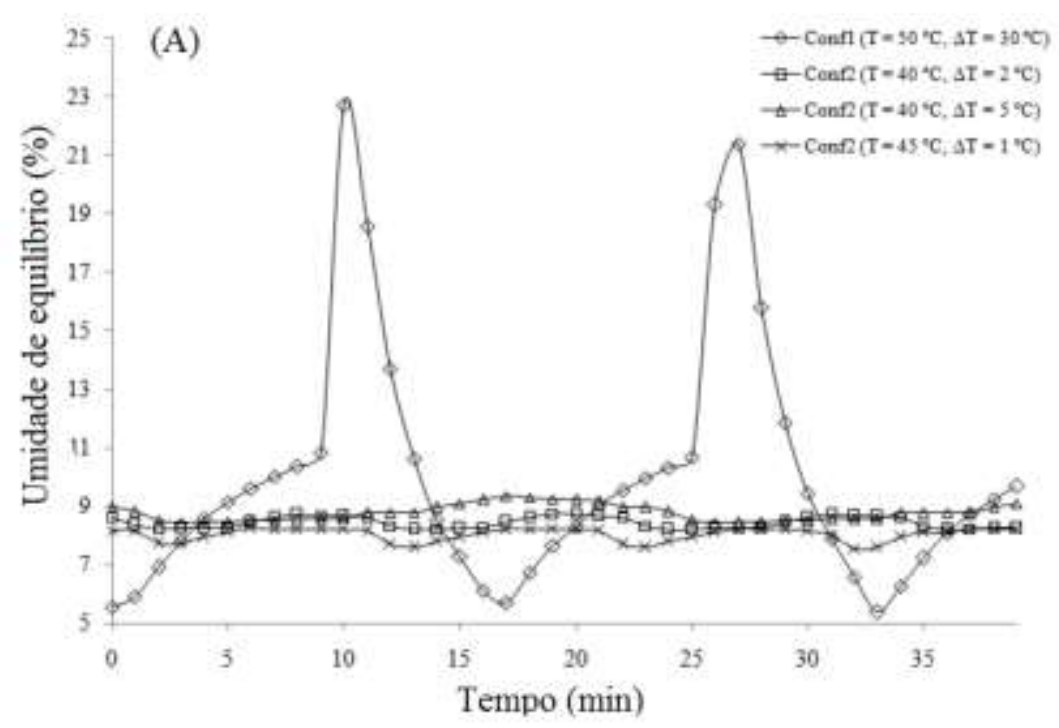

(B)

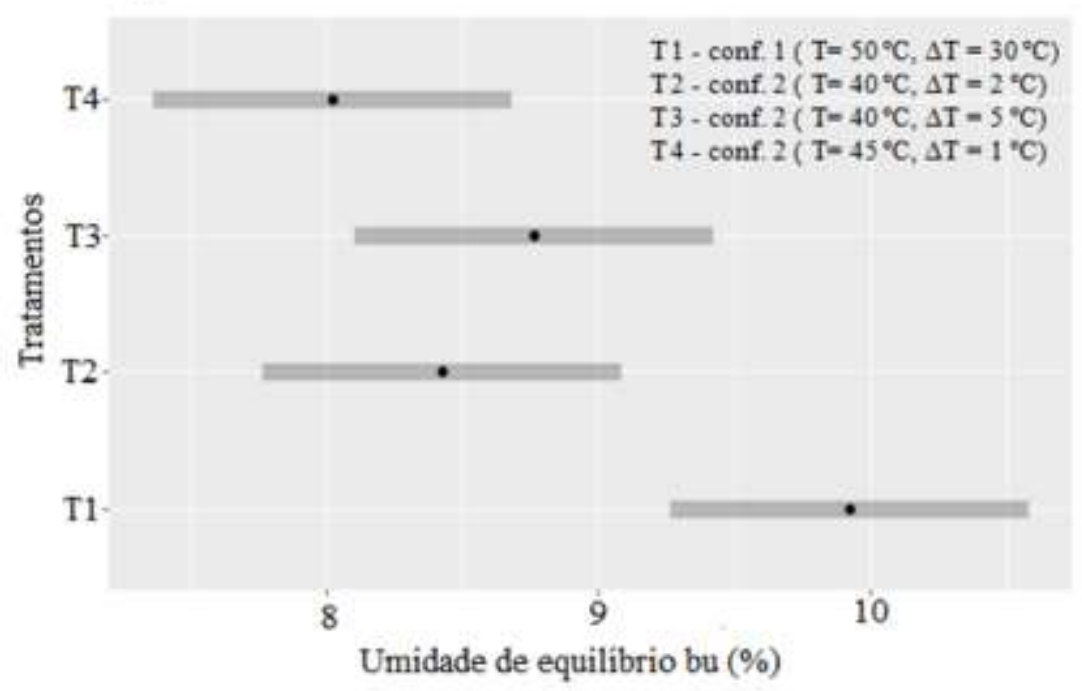

Fonte: Autores (2021).

A configuração 1 apresentou maior amplitude nos valores de umidade equilíbrio, com picos de quase $23 \%$ (Figura 10 A) e a maior média, igual a $9,92 \%$ (Figura 10B).

O teste de Tukey (Figura 10B) também apontou que não houve diferença significativa entre as médias de umidade de equilíbrio da configuração 1 (T1) e da configuração 2 na temperatura de $40{ }^{\circ} \mathrm{C}$ e diferencial de $5^{\circ} \mathrm{C}$ (T3), o que demonstra o efeito negativo do aumento do diferencial de temperatura em se obter ar com baixo valor de umidade de equilíbrio, como 
inicialmente constatado, quando da análise da Figura 8.

Por outro lado, a configuração 1 apresentou os menores valores mínimos de umidade de equilíbrio, próximos de 5\% (Figura 10A). Nessa configuração, conforme já comentado, o uso de um único trocador e a mudança brusca de função, agravou o problema de retorno de água para o ar. Se não fosse esse problema, considerando a tendência da curva de umidade relativa (Figura 5), esta poderia trabalhar com valores de umidade relativa entre 20 e $34 \%$.

A utilização de uma lógica de operação com a aplicação de um intervalo de tempo para a transição de função do trocador poderia minimizar esse problema. Isso também possibilitaria trabalhar com um diferencial de temperatura menor, uma vez que reduziria a frequência entre os ciclos. E, considerando os resultados obtidos para a configuração 2 , a redução do diferencial de temperatura na configuração 1 , também poderia resultar em benefícios para o processo.

No que diz respeito a questão de reabsorção de água na configuração 2, a utilização de um espaçamento entre o condensador e o evaporador e a restrição da bandeja de condensado apenas à base do evaporador, são medidas que ajudariam a minimizar o problema. O ajuste da velocidade do ar para evitar o arrasto de partículas de água para o condensador é outra medida que também pode colaborar para minimizar esse problema.

A configuração 2 foi a mais encontrada em trabalhos com secadores assistidos por bomba de calor (Strømmen et al., 2003; Teeboonma et al., 2003; Sarkar et al., 2006; Pal \& Khan, 2010; Patel e Kar, 2012; Housain et al., 2013; Zigler et al., 2013, Closas \& Villanueva, 2014; Aktas et al., 2014; Minea, 2015; Yuan et al., 2019; Ponwapee et al., 2021). Housain et al. (2013), trabalhando com temperatura de $37{ }^{\circ} \mathrm{C}$, obtiveram um valor de umidade média de 20\%. Ziegler et al. (2013) obtiveram um valor médio de umidade relativa de $12 \%$ numa temperatura de $33{ }^{\circ} \mathrm{C}$ e Pal e Khar relatam valores de umidade relativa abaixo de $40 \%$ para temperaturas entre 30 e $40{ }^{\circ} \mathrm{C}$. Dados estes que condizem com os resultados obtidos nesse trabalho.

\section{Considerações Finais}

A Configuração de montagem 2, com o condensador em série com o evaporador no circuito de ar, com a circulação se dando com o ar passando primeiramente no evaporador e depois no condensador, foi a que apresentou melhor desempenho no que diz respeito a gerar condições de temperatura e umidade relativa que resultem em baixos valores de umidade de equilíbrio do ar.

O diferencial de temperatura mostrou influência sobre as condições do ar de secagem. A diminuição do seu valor resultou em menor amplitude dos valores de temperatura, umidade relativa e umidade de equilíbrio do ar.

$\mathrm{Na}$ montagem de secadores baseados em tecnologia de bomba de calor, onde o evaporador vai trabalhar dentro do circuito do ar de secagem, deve ser dada atenção especial ao sistema de coleta e drenagem de água condensada pelo evaporador.

Para trabalhos futuros recomenda-se: explorar melhor as formas de operação na configuração 1, principalmente, no que diz respeito a maneira de transição da função do trocador de calor; trabalhar com um maior número de condições de operação (temperatura e diferencial de temperatura), para avaliar melhor a influência sobre as condições de secagem (temperatura, umidade relativa e umidade de equilíbrio do ar). Também, se recomenda estudar o efeito da variação da capacidade do sistema de refrigeração nas condições de secagem.

A configuração 1 não foi encontrada em nenhum trabalho da bibliografia pesquisada, o que demonstra a necessidade de mais estudos, principalmente, voltados a lógica de operação, tendo em vista que esta apresentou potencial para trabalhar com menores valores de umidade relativa. 
Research, Society and Development, v. 10, n. 16, e378101623929, 2021 (CC BY 4.0) | ISSN 2525-3409 | DOI: http://dx.doi.org/10.33448/rsd-v10i16.23929

\section{Agradecimentos}

A Fundação de Apoio ao Desenvolvimento do Ensino, Ciência e Tecnologia do Estado de Mato Grosso do Sul (FUNDECT), pelo apoio financeiro a pesquisa que originou o trabalho.

\section{Referências}

Aktas, M., Ceylan, I., Gürel, A. E. (2014). Testing of a Condensation-type Heat Pump System for Low-temperature Drying Applications. International Journal of Food Engineering, 10 (3), 521-531. doi: 10.1515/ijfe-2014-0124.

Alves, G. E., Isquierdo, E. P., Borém, F. M., Siqueira, V. C., Oliveira, P. D.; Anadrade, E. T. (2013). Cinética de secagem de café natural para diferentes temperaturas e baixa umidade relativa. Coffee Science, 8 (2), 238-247.

Borém, F. M., Isquierdo, E. P., Alves, G. E., Ribeiro, D. E., Siqueira, V. C., \& Taveira, J. H. D. S. (2018). Quality of natural coffee dried under different temperatures and drying rates. Coffee Science, 13 (2), 159-167. doi: 10.25186/cs.v13i2.1410.

Chung, D.S., Pfost, H.B. (1967). Adsorption and desorption of water vapors by cereal grains and their products Part II. Transactions of the ASAE, 10(1), 549551.

Closas, A. A., Villanueva, E. P. (2014). An experimental investigation of the fruit drying performance of a heat pump dryer. International Conference on Agriculture, Biology and Environmental Sciences (ICABES'14), 1, 8-9.

Coşkun, S., Doymaz, İ., Tunçkal, C., Erdoğan, S. (2016). Investigation of drying kinetics of tomato slices dried by using a closed loop heat pump dryer. Heat and Mass Transfer, 53(6), 1863-1871. doi:10.1007/s00231-016-1946-7.

Cruz, P. M. F. da, Braga, G. C., Grandi, A. M. de. (2012). Composição química, cor e qualidade sensorial do tomate seco a diferentes temperaturas. Semina: Ciências Agrárias, 33 (4), 1475-1486.

Dong, W., Hu, R., Chu, Z., Zhao, J., Tan, L. (2017). Effect of different drying techniques on bioactive components, fatty acid composition, and volatile profile of robusta coffee beans. Food Chemistry, 234 (1), 121-130.

Dong, W., Hu, R., Long, Y., Li, H., Zhang, Y., Zhu, K., Chu, Z. (2019). Comparative evaluation of the volatile profiles and taste properties of roasted coffee beans as affected by drying method and detected by electronic nose, electronic tongue, and HS-SPME-GC-MS. Food Chemistry, 272 (30), 723-731.

Gümüşay, O. A., Borazan, A. A., Ercal, N., Demirkol, O. (2015). Drying effects on the antioxidante properties of tomatoes and ginger. Food Chemistry, 173 (1), 156-162. doi:10.1016/j.foodchem.2014.09.162.

Hossain, M. A., Gottschalk, K., Hassan, M. S. (2013). Mathematical model for a heat pump dryer for aromatic plant. Procedia Engineering, 56 (1), 510-520.

Jeyaprakash, S., Heffernan, J. E., Driscoll, R. H., \& Frank, D. C. (2019). Impact of drying technologies on tomato flavor composition and sensory quality. LWT - Food Science and Technology, 120 (1), 1-11. doi:10.1016/j.lwt.2019.108888.

Jordan, R. A., Cortez, L. A. B., Barbin, D. F., Lucas Junior, J. (2016). Heat pump for thermal power production in dairy farm. Engenharia Agrícola, 36 (5), $779-791$.

Jordan, R. A., Yamasaki, J. T., Silveira Jr., V., Castelo Branco, E. D. (2019). Hybrid solar heat pump system for water heating. Engenharia Agrícola 39 (1), 419-425, 2019

Jordan, R. A., Siqueira, V. C., Quequeto, W. D., Cavalcanti-Mata, M. E. R., Hoscher, R. H., Mabasso, G. A., Battilani, M., Oliveira, F. C., Martins, E. A. S., Freitas, R. L. (2020a). Cinética de secagem de café natural e descascado a baixa temperatura e umidade relativa com emprego de uma bomba de calor. Research, Society and Development, 9(8). doi:10.33448/rsd-v9i8.5528.

Jordan, R. A., Siqueira, V. C., Quequeto, W. D., Cavalcanti-Mata, M. E. R. M., Hoscher, R. H., Mabasso, G. A., Battilani, M., Oliveira, F. C. de, Martins, E. A. S. \& Freitas, R. L. (2020b). Consumo específico de energia na secagem de café com sistema de aquecimento resistivo e bomba de calor. Research, Society and Development, 9(9), e303997297. doi: 10.33448/rsd-v9i9.7297

Jordan, R. A., Quequeto, W. D., Martins, E. A. S., Siqueira, V. C., Hoscher, R. H., Vital, R. S., Melo, C. O. M. (2020c). Cinética de secagem de tomate em secador convencional e bomba de calor. Research, Society and Development, 9(9), e810998024, doi: 10.33448/rsd-v9i9.8024.

Jordan, R. A., Siqueira, V. C., Cavalcanti-Mata, M. E. R. M., Hoscher, R. H., Mabasso, G. A., Quequeto, W. D., Battilani, M., Freitas, R. L., Oliveira, F. C., Martins, E. A. S. (2020d). Qualidade sensorial do café submetido a secagem a baixa temperatura e a frio com emprego de um sistema baseado em tecnologia de bomba de calor. Research, Society and Development, 9(11), e59791110302, doi: 10.33448/rsd-v9i11.10302.

Kulapichitr, F., Borompichaichartkul, C., Suppavorasatit, I., Cadwallader, K. R. (2019). Impact of drying process on chemical composition and key aroma components of Arabica coffee. Food Chemistry, 291(1), 49-58.

Patel, K. K., Kar, A. (2012). Heat pump assisted drying of agricultural produce - an overview. Journal of Food Sciencie Technology, 49 (2):142-160, doi: $10.1007 / \mathrm{s} 13197-011-0334-\mathrm{z}$.

Ponwapee, P., Somsila, P., Teeboonma, U., Namkhat, A., Pumchumpol, S. (2021). Thermal performance of heat pump dryer using R32 as refrigerant. Materials Science and Engineering. 1137(1), 1-11. doi: 10.1088/1757-899X/1137/1/012003 
Research, Society and Development, v. 10, n. 16, e378101623929, 2021

(CC BY 4.0) | ISSN 2525-3409 | DOI: http://dx.doi.org/10.33448/rsd-v10i16.23929

Lee, K.H., Kim, O.J., Kim, J. (2010). Performance simulation of a two-cycle heat pump dryer for high temperature drying. Drying Technology, 28 (1), 683689.

Lenth, R.V. (2021). Emmeans: Estimated Marginal Means, akaLeast-Squares Means. R packageversion 1.6.3. https://CRAN.R-project.org/package=emmeans

Lewis, D. (2003). High temperature dehumidification systems, US Patent 20030208923.

Mellmann, J., \& Fürll, C. (2008). Drying facilities for medicinal and aromatic plants-specific energy consumption and potential for optimisation. Zeitschrift fur Arznei-\& Gewurzplanzen, 13(3), 127-133.

Minea, V. (2011). Industrial drying heat pumps in refrigeration: Theory, technology and applications. Nova Science Publishers: Hauppauge, NY, 1-70.

Minea, V. (2015). Overview of heat-pump-assisted drying systems, part I: integration, control complexity, and applicability of new innovative concepts, Drying Technology, 1, 1-12. doi: 10.1080/07373937.2014.952377.

Pal, U. S., Khan, M.K. (2010). Performance evaluation of heat pump dryer. Journal of Food Science Technology, 47 (2), 230-234.

R Development Core Team. R: Language and Environment for Statistical Computing.R Foundation for Statistical Computing, 2014. http://www.R-project.org

Sarkar, J., Bhattacharyya, S., Gopal, R. (2006). Transcritical $\mathrm{CO}_{2}$ Heat Pump Dryer: Part 2. Validation and Simulation Results. Drying Technology, 24 (1), 1593-1600, , doi: 10.1080/07373930601030945.

Strømmen, I., Eikevik, T.M., Alves-Filho, O., Syverud, K., Jonassen, O. (2003). "Low temperature Drying with Heat Pumps - New Generations of High Quality Dried products". The 2nd Nordic Drying Conference, Copenhagen Denmark.

Taşeri, L., Aktas, M., Şevik, S., Gülcü, M., Seçin, G. U., Aktekeli, B. (2018). Determination of drying kinetics and quality parameters of grape pomace dried with a heat pump dryer. Food Chemistry, 260 (15), 152-159.

Teeboonma, U., Tiansuwan, J., Soponronnarit, S. (2003). Optimization of heat pump fruit dryers. Journal of Food Engineering, 59(4), 369-377. doi: $10.1016 / \mathrm{S} 0260-8774(02) 00496-\mathrm{X}$.

Yuan, Y., Lin, W., Mao, X., Li, W., Yang, L., Wei, J., Xiao, B. (2019). Performance analysis of heat pump dryer with unit-room in cold climate regions. Energies, 12(1), 3125. doi:10.3390/en12163125.

Ziegler, T., Jubaer, H., \& Mellmann, J. (2013). Simulation of a heat pump dryer for medicinal plants. Chemie Ingenieur Technik, 85(3), 353-363. doi: $10.1002 /$ cite. 201200123 